\title{
A Research on Fresh-Keeping Strategies for Fresh Agricultural Products from the Perspective of Green Transportation
}

\author{
Guangshu Xu $\mathbb{D}^{1},{ }^{1}$ Hao Wu, ${ }^{1}$ Yongsheng Liu $\mathbb{D}^{2},{ }^{2}$ Chia-Huei Wu, ${ }^{3}$ and Sang-Bing Tsai $\mathbb{D}^{4,5}$ \\ ${ }^{1}$ School of Logistics, Beijing Wuzi University, Beijing 101149, China \\ ${ }^{2}$ School of Business, Beijing Wuzi University, Beijing 101149, China \\ ${ }^{3}$ Institute of Service Industries and Management, Minghsin University of Science and Technology, Hsinchu 304, Taiwan \\ ${ }^{4}$ Zhongshan Institute, University of Electronic Science and Technology, Zhongshan, China \\ ${ }^{5}$ Research Center for Environment and Sustainable Development of China Civil Aviation, Civil Aviation University of China, \\ Tianjin, China
}

Correspondence should be addressed to Yongsheng Liu; liuyongsheng@bwu.edu.cn and Sang-Bing Tsai; sangbing@hotmail.com

Received 4 June 2019; Revised 26 August 2019; Accepted 5 September 2019; Published 26 February 2020

Academic Editor: Francisco R. Villatoro

Copyright (C) 2020 Guangshu Xu et al. This is an open access article distributed under the Creative Commons Attribution License, which permits unrestricted use, distribution, and reproduction in any medium, provided the original work is properly cited.

\begin{abstract}
This paper studies the impact of fresh-keeping effort (FKE) investment strategies from the perspective of green transportation on a fresh-product supply chain (FSC) system for the purpose of reducing the emission of harmful gases and waste of resources. A supplier-buyer structure in an FSC system is modeled under two approaches consisting of the fixed FKE model and the variable FKE model. Then the paper analyzes the effect of optimal FKE level on retailer's profit and product freshness under two different approaches, and finds that there is space to be improved in the two approaches which were further optimized. Finally, the proposed models are approved with a dataset from a real-life case study. Under the above two approaches, not only profits can be increased in retail enterprises but also the freshness level of fresh agricultural products (FAP) can be improved and reduced the consumption of resources. The results show that there is an optimal investment level of FKE under different strategies, and the maximum profit could be obtained by keeping fresh at this level. Moreover, the fixed FKE will not increase the average freshness of fresh produce in a sales cycle, and the adjusted FKE can effectively improve the average freshness.
\end{abstract}

\section{Introduction}

Green transportation refers to the green development of transport activity by reducing the environmental pollution and the consumption of resources, promoting the green degree of transportation process and transportation management [1]. The environmental pollution of transport activity is mainly embodied in the greenhouse gas emissions, a large amount of carbon dioxide emissions will be generated in the whole logistics activities from production to sales, which brings many environmental problems such as greenhouse effect, extreme climate, air pollution etc., [2]. Meanwhile, in the process of transport activities, the inevitable factors will lead to product damage and the losses of quality, resulting in unnecessary resource consumption that increases the costs. Implementing green transportation can effectively reduce the losses of transport activities on the environment and product quality. Fresh agricultural products (FAP), as perishable products, will continuously produce carbon dioxide through respiration after being harvested. With the constant consumption of nutrients and water in the products, the freshness degree of the products declines, and the resource utilization of the products decreases gradually too. It is necessary to do research on the fresh-keeping effort from the perspective of green transportation for the environment. Freshness, as a factor of visual inspection of agri-products, not only reflects the amount of carbon dioxide emissions in the circulation process but also indicates the rate of resource utilization. Effectively controlling the decline of agri-product freshness is an important indication to reduce pollution emissions and improve resource utilization in the process of agri-product transportation.

In addition to considering the impact on the environment, the decline in freshness of FAP maybe brings great harm to the profits of retailer. The decrease in freshness will seriously 
affect the appearance and the quality of FAP, manifested as loss of water and nutritional value, and other deterioration of products, greatly reducing consumers' desire to purchase, to be sold at a lower price, ultimately lower retailer profits [3]. With the continuous improvement in consumers' requirements for FAP quality, freshness as an important indicator reflecting the quality of products has already become the criterion for consumers to choose fresh agricultural products. Based on the core views of green transportation, the fresh-keeping treatment of FAP has become an important way to reduce harmful gas emissions, to cut down resource loss and improve freshness during the transportation process. Fresh-keeping treatment can effectively slow down the decline of freshness and improve the quality of products [4], which not only meets the needs of consumers for FAP, stimulates consumers' desire to purchase, improves the profits of retail enterprises, but also reduces the emission of harmful gases, reduce waste of agricultural resources. It is an important theoretical value and practical significance for consumers, businesses, and society [5] of the research.

Although the investment in FKE can effectively delay the decline rate of corruption of FAP, the normal operation of FKE requires a considerable amount of fresh-keeping costs, and the costs of fresh-keeping increases with the difficulties of FKE. Therefore, this paper will study the FKE of high-loss fresh agri-products in transportation from the perspective of green logistics, and establish a mathematical model to solve the problem under the full consideration of relevant factors, in order to improve the freshness of agri-products on the basis of improving profits involved. In order to improve the freshness of agri-products on the basis of improving the profit of products, and to achieve the purpose of reducing the loss of resources and harmful gases, it provides a reference from the respect of relevant retails to make fresh-keeping decisions.

In brief, the main contributions of this study relative to other similar studies are as follows:

(1) To create a model more close to reality, the market demand is affected by both freshness and quality of products in this paper, and suppose that the retailer would adjust the sales price according to the freshness degree, price function influenced by freshness is considered.

(2) In order to show the freshness change affected by the different FKE strategy, this paper creates the calculation function of the average freshness degree.

(3) This paper puts forward a variable FKE strategy, and optimizes the strategy to analyze the advantages in retailer profit and freshness.

The rest of the paper is organized as follows. In Section 2, the literatures on the decision-making of agri-products FKE are reviewed. In Section 3, the issues to be studied in this paper are described. In Section 4, two decision models are constructed: the fixed FKE model and the variable FKE model; the two models are analyzed and optimized based on the analysis results. In Section 5, the proposed models are empirically tested with the numerical example. Section 6 is devoted to conclusions and future research trends.

\section{Literature Review}

Several scholars researched the decision-making related to the fresh-keeping of agricultural products. The majority of existing studies focus on the coordination of FKE from the view of the supply chain of fresh agri-products. Cai et al. [6] and Cao et al. [7] proposed to encourage suppliers in the supply chain to intensify their FKE and strengthen cooperation by devising effective contract-based incentives. On this basis, Liu et al. [8] explored the optimal decision-making for inputting FKE in the supply chain using the differential games method. Lin et al. [9] designed a return sharing contract based on the considerations of loss control and of ensuring the freshness of fresh agricultural products, with the aim of stimulating the input of FKE at every link of the supply chain. Wang and Dan [10], Ma et al. [11], and Zhang and Zhang [12] designed the "wholesale price + fresh-keeping cost sharing" contract, the "cost sharing + return sharing" contract, and the "fresh-keeping cost sharing + risk compensation + return sharing" contract to enhance the FKE of all parties involved in the supply chain. Feng et al. [13] explored how to improve the freshness of fresh agricultural products utilizing the special facilities and specialized skills of third-party logistics (TPL) service providers, and studied the supply chain coordination mechanism of a TPL-dominated supply chain [14]. Furthermore, Yao et al. explored how to incentivize TPL service providers to keep the agricultural products fresh in the outsourced logistics service from the perspective of retailers [15]. Xu and Song [16] studied how TPL service providers may fail to provide an adequate fresh-keeping service in the secondary supply chain composed of e-commerce and logistics service providers of fresh agricultural products, and proposed to design coordination contracts using cost sharing and return sharing schemes to enhance the fresh-keeping service of logistics service providers. In summary, previous studies on FKE [5-11] have primarily concentrated on the coordination of the FKE in the supply chain of fresh agricultural products, that is, to coordinate and stimulate the FKE of upstream suppliers and logistics service providers through contracts. At retail outlets, which represent the last link of the supply chain, the freshness of the agricultural products has a huge impact on the profitability of the retailers. Therefore, some scholars have also studied the FKE of agricultural products retailers. Dye and Hsieh [17] proved that the retailer's profit per unit time is a convex function of its FKE, and calculated the amount of FKE required to achieve the maximum unit profit. On this basis, Lee and Dye [18] used examples to demonstrate the importance of retailers' FKE, and established a retailer optimal FKE model. On the basis of the results of Lee and Dye, Wang and Dan [19] considered the diversity of consumer preferences, and analyzed the optimal pricing strategy and the optimal level of FKE for agricultural product retailers. Other studies [16-18] treat the entire fresh-keeping process related to retailing as a whole, and obtain the optimal fresh-keeping strategy by solving the profit maximization 
TABLE 1: This paper versus the FSC literature.

\begin{tabular}{|c|c|c|c|c|c|}
\hline \multirow[b]{2}{*}{ Reference } & \multicolumn{3}{|c|}{ Demand sensitive to } & \multirow{2}{*}{$\begin{array}{c}\text { Decision } \\
\text { FKE }\end{array}$} & \multirow{2}{*}{$\begin{array}{c}\text { Variables } \\
\text { FKE } \\
\text { adjustment } \\
\text { point } \\
\end{array}$} \\
\hline & $\begin{array}{l}\text { Freshness- } \\
\text { affected } \\
\text { prices }\end{array}$ & $\begin{array}{c}\text { Fresh- } \\
\text { ness }\end{array}$ & Price & & \\
\hline$[3]$ & & $*$ & $*$ & & \\
\hline [9] & & $*$ & & & \\
\hline$[11]$ & & & $*$ & $*$ & \\
\hline [13] & & $*$ & * & $*$ & \\
\hline$[14]$ & & $*$ & * & $*$ & \\
\hline$[23]$ & & $*$ & & & \\
\hline$[22]$ & & $*$ & * & & \\
\hline This paper & $*$ & $*$ & $*$ & $*$ & $*$ \\
\hline
\end{tabular}

model. Affected by freshness, the difference between the earlier sales profit with higher freshness and the later sales profit with lower freshness is obvious. Therefore, according to the actual situation of sales, it is more in line with the reality of retailers to adjust the retailer's freshness efforts properly. Hence, a retailer can maximize its profit by adjusting its FKE level according to the actual situation [20]. Ghazanfari et al. [21] studied the impact of government's incentives on a FSC system under two different approaches including TSC and MSC. Mohammadi et al. [22] designed a revenue and preservation-technology investment sharing to motivate the members to participate in the centralized model.

In summary, Table 1 classifies the current FSC literature.

Table 1 demonstrates that the related works in the FSC system have assumed that the demand can be influenced by the price, FKE, and/or a combination of them. Taking a different viewpoint, in this paper, the market demand is simultaneously dependent on the FKE and price while freshness also affects price. Table 1 shows that far too little attention has been paid to the application of variable FKE, which this paper extends to. Therefore, it is a theoretical innovation and practical significance to incorporate the retailer's FKE into the fresh agricultural product sales model, to adjust the fresh-keeping strategy according to the freshness degrees of the products, and to compare the effects of different fresh-keeping strategies on profitability and product freshness.

Investigation of the green transportation in the supply chain is another area of the literature related to our study. With the concern of environmental issues, green transportation has gradually attracted the attention of logistics scholars. As an important indicator of environmental protection, carbon emissions have been considered. In order to reduce the carbon emissions of the products in the process of production [6], transportation [24], storage [25], scholars make decisions on product production, transportation, and EOQ models under the introduction of carbon emission constraints and carbon tradable mechanisms [26], Studies have shown that scientific production, transportation, and EOQ decisions can effectively reduce the environmental impact of carbon emissions. In addition to considering the impact of carbon emission, consumers' environmental awareness, and environmental protection preferences are also taken into consideration. For example, Yongmei and Xie [27] analyzed the impact of consumer environmental awareness on demand, established a closed-loop supply chain model, coordinated the supply chain through revenue sharing contracts, and found that the introduction of consumer environmental awareness effectively improved the environmental protection of node enterprises. Level. Ji et al. [23] analyzed a two-channel supply chain consisting of a manufacturer and a retailer. Taking into account consumer green preferences and sales efforts, the consumer utility function was used to establish a profit model of manufacturers and retailers, and optimal emission reduction strategy is obtained [28-32].

Liu et al. [33] considered both the production competition between partially substitutable products made by different manufacturers, and the competition between retail stores, and they found that as consumers' environmental awareness increases, retailers and manufacturers with superior ecofriendly operations will benefit [33-36]. Ghosh and Shah [37] studied supply chain coordination issues arising out of green supply chain initiatives and explored the impact of cost sharing contract on the key decisions of supply chain players undertaking green initiatives. Although the concept of green SC has been widely used on the manufacturing industry, there has been limited used on FAP. Fresh agricultural products are deteriorating products, which produce carbon dioxide due to the influence of respiration during the process of reducing freshness. At the same time, the decrease in freshness also causes the product corruption rate to rise, resulting in waste of resources. Delaying the decline of freshness can reduce the impact on the environment. Therefore, this paper intends to improve the freshness of products in transportation activities and reduce the impact of agricultural logistics activities on the environment from the perspective of green transportation.

\section{Problem Description and Hypothesis}

In this paper, the focus of research is on the issue of FKE at the end of the fresh agricultural product supply chain. In order to reduce the impact on the profit and the environment caused by the decline in freshness, retailers often take measures to keep the agricultural products fresh, but the investment in FKE needs costs, the relationship between cost and FKE is exponentially increasing [38-42]. Therefore, this paper studies the optimal FKE strategy of fresh produce retailers. Before discussing this issue, it is necessary to study the characteristics and regularity of the freshness change of fresh produce [43-46].

In order to construct the freshness function, this paper draws on the description of the law of freshness change in the relevant literature and combines the actual situation of freshness change in real life [47-49]. The summary of the freshness function of fresh agricultural products has the following characteristics:

(1) The key factors affecting freshness are the time $t$ and the level of FKE $\tau$;

(2) The variation of freshness declines with an accelerated speed, the function should satisfy these two conditions: $\partial \theta / \partial t<0$, and $\partial^{2} \theta / \partial t^{2}<0[1]$;

(3) As the difficulty of preservation increases, the effect of preservation decreases gradually: $\partial \theta / \partial t<0$, $\partial^{2} \theta / \partial t^{2}<0$ 
(4) Since fresh agricultural products have a certain life cycle, the construction function should ensure that the sales time $t$ changes during the product life cycle. Beyond this range, the product rots and has no discussion significance.

According to the characteristics of freshness change, based on the freshness model $\theta_{(t)}=1-[t / T]^{2}$ in the reference [21], the integrated fresh agricultural products undergo transportation, packaging, and other products before sale. The freshness will have a certain degree of decline in the actual situation. Assuming that the initial freshness of the product is $\theta_{0}<1$, the range of product freshness during sales is $\left[0, \theta_{0}\right]$, and the rebuild freshness function is:

$$
\theta_{(t, \tau)}=\theta_{0}-\theta_{0}\left[\frac{t}{T_{0}(1+\alpha \tau)}\right]^{2}=\theta_{0}-\theta_{0}\left[\frac{t}{T}\right]^{2} .
$$

Only fresh produce in the life cycle can attract consumers, so the sales time should be satisfied. $t \in[0, T]$.

In order to compare the effects of different fresh-keeping strategies on product freshness, this paper uses the average freshness degree to evaluate the overall freshness variation trend under each fresh-keeping strategy. The average freshness degree description model established in this study is as follows:

$$
\bar{\theta}=\left.\frac{\int\left(\theta_{t}\right) d t}{t}\right|_{0} ^{T}
$$

The model performs at first an integration operation on the freshness degree within the fresh-keeping period $T$, and then uses the ratio of the integral value to the sales time $T$ as the average freshness degree within the fresh-keeping period. The model can objectively describe the freshness degree of the product in the sales period.

Other assumptions include:

Hypothesis 1: It was assumed that the retailer uses a multi-pricing sales strategy to sell the product, with the retail price gradually dropping with the progression of sales time [22]. Under this sales strategy, the selling price satisfies the following condition:

$$
P_{(t)}=\frac{k_{0} P_{0} \cdot \operatorname{INT}\left(\theta_{t} \times 10\right)}{10},
$$

where $\operatorname{INT}\left(\theta_{t} \times 10\right)$ represents the rounding function for the freshness degree. For the convenience of calculation, this paper uses the approximation of the continuous function to replace the above piecewise function, that is, the price function is assumed to be the following:

$$
P_{t}=k_{0} \theta_{t} P_{0} .
$$

Hypothesis 2: On the basis of the research result of reference [5], it was assumed that the purchase volume at any given time $t$ is the following:

$$
D_{t}=\lambda\left(U_{0}-a P_{t}+b \theta_{t}\right),
$$

where $U_{0}, a$, and $b$ all comply with a $[0,1]$ even distribution.
Hypothesis 3: Due to the increase in the difficulty of fresh-keeping, the FKC and the level of FKE exhibit a quadratic function relationship. Aside from the level of $\mathrm{FKE} \tau$, the fresh-keeping time is another important factor affecting the cost of fresh-keeping. The FKC is positively correlated with both the level of FKE and the fresh-keeping time. Thus, the FKC function established in this study is the following:

$$
c_{(\tau)}=\frac{1}{2} \beta \tau^{2} t
$$

\section{Model Construction}

4.1. Basic Model of FKE. Based on the above hypotheses, Based on the above assumptions, the retailer's sales revenue function during the period $(0-t)$ is:

$R_{t}=\int\left(D_{t} \times P_{t}\right) d_{t}=\left(N \theta_{0}+M \theta_{0}^{2}\right) t-\frac{N \theta_{0}+2 M \theta_{0}^{2}}{3 T^{2}} t^{3}+\frac{M \theta_{0}^{2}}{5 T^{4}} t^{5}$.

The function of the retailer's sales volume is the following:

$$
Q_{t}=\int D_{t} d_{t}=\frac{N+M \theta_{0}}{k_{0} P_{0}} t-\frac{M \theta_{0}}{3 k_{0} P_{0} T^{2}} t^{3},
$$

where $N=\lambda k_{0} P_{0} U_{0}, M=\lambda k_{0} P_{0}\left(b-a k_{0} P_{0}\right)$.

4.1.1. NonFKE Strategy. When not keeping fresh, $\tau=0, T=T_{0}$, then the retailer's sale profit is equal to the sales income minus the purchase cost and other costs associated with purchase. Thus, the profit under the condition of zero FKE is the following:

$$
\begin{aligned}
L_{s_{0}}= & \left(N \theta_{0}+M \theta_{0}^{2}-\frac{N \theta_{0}+2 M \theta_{0}^{2}}{3}+\frac{M \theta_{0}^{2}}{5}\right) T_{0} \\
& -\left(\frac{N+M \theta_{0}}{k P_{0}}-\frac{M \theta_{0}}{3 k P_{0} T^{2}}\right) w T_{0}-C_{x}=\left(A_{1}-A_{2}\right) T_{0}-C_{x} .
\end{aligned}
$$

The profit in a unit time period is $L_{s_{0}} / T_{0}$.

The average freshness degree was calculated in the following way:

$$
\overline{\theta_{s_{0}}}=\left.\frac{\int \theta_{0}-\left(\theta_{0} / T^{2}\right) t^{2} d t}{t}\right|_{0} ^{T_{0}}=\theta_{0}-\frac{1}{3} \theta_{0}=\frac{2}{3} \theta_{0} .
$$

4.1.2. Fixed FKE Strategy. Under the condition of fixed FKE strategy, the retailer's profit is equal to the sales income minus the purchase cost, the FKC, and other costs associated with purchase. Thus, the sales profit function of selling the fresh agricultural product in a sales cycle is the following:

$$
\begin{aligned}
L_{s_{1}}= & \left(N \theta_{0}+M \theta_{0}^{2}-\frac{N \theta_{0}+2 M \theta_{0}^{2}}{3}+\frac{M \theta_{0}^{2}}{5}\right) T \\
& -\left(\frac{N+M \theta_{0}}{k P_{0}}-\frac{M \theta_{0}}{3 k P_{0}}\right) w T-\frac{\beta}{2} \tau^{2}(1+\tau \alpha) T_{0}-C_{x} \\
= & \left(A_{1}-A_{2}\right)(1+\tau \alpha) T_{0}-\frac{\beta}{2} \tau^{2}(1+\tau \alpha) T_{0}-C_{x} .
\end{aligned}
$$


Since $\left(\partial^{2} L_{s_{1}} / \partial^{2}\right)=-\beta T_{0}-3 \alpha \beta T_{0} \tau<0$, let $(\partial L / \partial \tau)=\left(A_{1}-A_{2}\right)$ $\alpha T_{0}-\beta T_{0} \tau-(3 \alpha \beta / 2) T_{0} \tau^{2}=0$, the optimal FKE under this condition is the following:

$$
\tau^{*}=\frac{1}{3 \alpha} \sqrt{1+\frac{6 \alpha^{2}\left(A_{1}-A_{2}\right)}{\beta}}-\frac{1}{3 \alpha} .
$$

$L_{s_{1}}{ }^{*}\left(\tau^{*}\right)$ is the optimal profit under the fixed effort fresh-keeping strategy, while $L_{s_{1}}{ }^{*}\left(\tau^{*}\right) / T$ is the profit in a unit time period.

The average freshness degree was calculated in the following way:

$$
\overline{\theta_{S_{1}}}=\left.\frac{\int \theta_{0}-\left(\theta_{0} / T^{2}\right) t^{2} d t}{t}\right|_{0} ^{T}=\theta_{0}-\frac{1}{3} \theta_{0}=\frac{2}{3} \theta_{0} .
$$

Proposition 1. There is an optimal FKE in a sales cycle, and the optimal FKE will yield the maximum profit. When the optimal FKE is $\tau^{*}=(1 / 3 \alpha) \sqrt{1+6 \alpha^{2}\left(A_{1}-A_{2}\right) / \beta}-(1 / 3 \alpha)$, the maximum profit is $L_{s_{1}}{ }^{*}\left(\tau^{*}\right)$.

Proposition 2. Under the condition of fixed effort input in fresh-keeping, the optimal FKE is directly proportional to the initial freshness of the product.

Proof. $A_{1}-A_{2}=(8 / 15) M \theta_{0}{ }^{2}+\left((2 / 3) N-\left(2 M W / 3 k_{0} P_{0}\right)\right)$ $\theta_{0}-\left(N W / k_{0} P_{0}\right)$. A derivation was performed on $\theta_{0}$ to obtain $\left(A_{1}-A_{2}\right)=(16 / 15) M \theta_{0}+(2 / 3) N-\left(2 M W / 3 k_{0} P_{0}\right)$. It can be deduced from Eq. (3) that $P_{\theta_{0}}=k_{0} \theta_{0} P_{0}$. When the product freshness is $\theta_{0}$, the selling price is $P_{\theta_{0}}>w$ and $\theta_{0}<1$, hence $\left(W / k_{0} P_{0}\right)<1$ and $\left(2 M W / 3 k_{0} P_{0}\right)<(2 / 3) M$. It can be, deduced from Eq. (4) that $\mathrm{N}>\mathrm{M}>0$, hence $\left(A_{1}-A_{2}\right)=(16 / 15) M \theta_{0}+(2 / 3) N-\left(2 M W / 3 k_{0} P_{0}\right)>$

$(16 / 15) M \theta_{0}+(2 / 3) N-(2 / 3) M>0, \theta_{0}$ is positively correlated with $A_{1}-A_{2} . \quad A_{1}-A_{2}$ is positively correlated with $\tau^{*}$, hence $\theta_{0}$ is positively correlated with $\tau^{*}$.

Proposition 2 indicates that when a retailer adopts the fixed effort fresh-keeping strategy to preserve agricultural products, the profit can be maximized by determining the FKE input according to the initial freshness of the product. The higher the initial freshness of the product, the larger the FKE input, and vice versa.

Proposition 3. The FKE should be maintained in the range $\left[0,(1 / 2 \alpha) \sqrt{1+\left(8 \alpha^{2}\left(A_{1}-A_{2}\right) / \beta\right)}-(1 / 2 \alpha)\right]$. When the FKE value $\tau<(1 / 2 \alpha) \sqrt{1+\left(8 \alpha^{2}\left(A_{1}-A_{2}\right) / \beta\right)}-(1 / 2 \alpha)$, a fresh-keeping gain will be created. If $\tau>(1 / 2 \alpha) \sqrt{1+\left(8 \alpha^{2}\left(A_{1}-A_{2}\right) / \beta\right)}-(1 / 2 \alpha)$, then the sales profit will decrease.

Proof. If the profit is increased by making a FKE $\tau$, then $L_{s_{1}}^{*}-L_{s_{0}}=\left(A_{1}-A_{2}\right) \alpha T_{0} \tau-(\beta / 2) T_{0} \tau^{2}-(\alpha \beta / 2) T_{0} \tau^{3}>0$ and $-(1 / 2 \alpha) \sqrt{1+\left(8 \alpha^{2}\left(A_{1}-A_{2}\right) / \beta\right)}-(1 / 2 \alpha)<\tau<(1 / 2 \alpha)$ $\sqrt{1+\left(8 \alpha^{2}\left(A_{1}-A_{2}\right) / \beta\right)}-(1 / 2 \alpha)$. To ensure that the FKE is meaningful, let $0<\tau<(1 / 2 \alpha) \sqrt{1+\left(8 \alpha^{2}\left(A_{1}-A_{2}\right) / \beta\right)}-(1 / 2 \alpha)$, which means that the sales profit will be increased when the FKE falls into this range. When the FKE $\tau>(1 / 2 \alpha) \sqrt{1+\left(8 \alpha^{2}\left(A_{1}-A_{2}\right) / \beta\right)}-(1 / 2 \alpha), L_{\left(s_{1}\right)}^{*}-L_{\left(s_{0}\right)}^{*}<0$. In this case, a high-level FKE entails a high FKC; however, the extra income generated by the FKE is not enough to offset the FKC. Hence, when the FKE exceeds $(1 / 2 \alpha) \sqrt{1+\left(8 \alpha^{2}\left(A_{1}-A_{2}\right) / \beta\right)}-(1 / 2 \alpha)$, the retailer's sales profit will decrease.

Proposition 3 indicates that retailers need to determine the level of FKE based on the actual situation of sales, because the cost of fresh-keeping increases exponentially with the increase in FKE. Only when $0<\tau<(1 / 2 \alpha)$ $\sqrt{1+\left(8 \alpha^{2}\left(A_{1}-A_{2}\right) / \beta\right)}-(1 / 2 \alpha)$ the fresh-keeping gain generated by retailers' FKE can exceed the FKC, and the overall profitability will increase. When $\tau>(1 / 2 \alpha)$ $\sqrt{1+\left(8 \alpha^{2}\left(A_{1}-A_{2}\right) / \beta\right)}-(1 / 2 \alpha)$, the FKC will outweigh the fresh-keeping gain, leading to a decrease of profit.

4.1.3. Variable Effort Input in Fresh-Keeping. As the freshness declines during the sales process, the market demand and the selling price will change at different sale stages. Inputting a fixed amount of FKE is clearly insufficient to maximize the profit in a dynamic sales process. Therefore, this paper proposes to adjust the FKE input during the sale process of fresh agricultural products, and more specifically, to switch between two FKE levels according to the actual sales situation. The method to determine the optimal fresh-keeping level at each stage and the freshness variation of fresh agricultural products are studied in the following way.

$\tau_{1}$ and $\tau_{2}$ represent, respectively, the FKE levels at the first stage and second stage under the variable effort fresh-keeping strategy. $T_{1}$ and $T_{2}$ are the first stage period and second stage period, respectively. $T_{1}=k_{1}\left(1+\alpha_{1} \tau_{1}\right) T_{0}$ and $T_{2}=\left(1-k_{1}\right)\left(1+\alpha_{2} \tau_{2}\right) T_{0}$; thus, the adjustment point is $\theta_{1}=\left(1-k_{1}^{2}\right) \theta_{0}$.

(1) The first fresh-keeping stage $T_{1}=k_{1} T_{0}$.

The sales income and the sales volume were calculated as follows:

$$
\begin{aligned}
\int_{0}^{T_{1}} D_{t} P_{t} d_{t}= & \left(N \theta_{0}+M \theta_{0}^{2}\right) t-\frac{N+2 M \theta_{0}^{2}}{3+\left(1+\alpha \tau_{1}\right)^{4} T_{0}^{4}} t^{3} \\
& +\left.\frac{M \theta_{0}^{2}}{5+\left(1+\alpha \tau_{1}\right)^{2} T_{0}^{2}} t^{5}\right|_{0} ^{T_{1}} \\
= & {\left[\left(N \theta_{0}+M \theta_{0}^{2}\right) k_{1}-\frac{N \theta_{0}+2 M \theta_{0}^{2}}{3} k_{1}^{3}+\frac{M \theta_{0}^{2}}{5} k_{1}^{5}\right] T_{1} } \\
= & A_{3}\left(1+\alpha \tau_{1}\right) T_{0} \\
\int_{0}^{T_{1}} D_{(t)} d_{t}= & \frac{N+M \theta_{0}}{k_{0} P_{0}} t-\left.\frac{M \theta_{0}}{3 k_{0} P_{0}\left(1+\alpha \tau_{1}\right)^{2} T_{0}^{2}} t^{3}\right|_{0} ^{T_{1}} \\
= & \left(\frac{N+M \theta_{0}}{k_{0} P_{0}} k_{1}-\frac{M \theta_{0}}{3 k_{0} P_{0}} k_{1}^{3}\right)\left(1+\alpha \tau_{1}\right) T_{0} .
\end{aligned}
$$

The purchase cost was considered as equal to $D_{1} w=$ $\left(\left(N+M \theta_{0} / k_{0} P_{0}\right) k_{1}-\left(M \theta_{0} / 3 k_{0} P_{0}\right) k_{1}^{3}\right) w\left(1+\alpha \tau_{1}\right) T_{0}=A_{4}$ $\left(1+\alpha \tau_{1}\right) T_{0}$, while the FKC was considered as equal to $(\beta / 2) \tau_{1}^{2} k_{1}\left(1+\alpha \tau_{1}\right) T_{0}$. 
(2) The second fresh-keeping stage $T_{2}$.

The sales income and the sales volume were calculated in the following way: $\int_{0}^{T_{2}} D_{t} P_{t} d_{t}=\left(N \theta_{1}+M \theta_{1}^{2}\right) t$ $-\left(N \theta_{1}+2 M_{1}{ }^{2} / 3 T_{2}{ }^{2}\right) t^{3}+\left.\left(M \theta_{1}{ }^{2} / 5 T_{2}^{4}\right) t^{5}\right|_{0} ^{T_{2}}=\left[\left(N \theta_{1}+M \theta_{1}{ }^{2}\right)\right.$ $\left.-\left(N \theta_{1}+2 M_{1}^{2} / 3\right) t^{3}+\left(M \theta_{1}^{2} / 5\right)\right] T_{2}=A_{5} T_{2} D_{2}=\int_{0}^{T_{2}} D_{t} d_{t}$ $=\left(N+M \theta_{1} / k_{0} P_{0}\right) t-\left.\left(M \theta_{1} / 3 k_{0} P_{0} T_{1}^{2}\right) t^{3}\right|_{0} ^{T_{2}}=((N+$ $\left.\left.M \theta_{1} / k_{0} P_{0}\right)-\left(M \theta_{1} / 3 k_{0} P_{0}\right)\right) T_{2}$.

The purchase cost was considered as equal to $D_{2} w=$ $\left(3 N+2 M \theta_{1} / 3 k_{0} P_{0}\right) w T_{2}=A_{6} T_{2}$.

The total profit of under the variable effort fresh-keeping strategy was calculated with the following formula:

$$
\begin{aligned}
L_{s_{2}}= & {\left[\left(N \theta_{0}+M \theta_{0}^{2}\right) k_{1}-\frac{N \theta_{0}+2 M \theta_{0}^{2}}{3} k_{1}^{3}+\frac{M \theta_{0}^{2}}{5} k_{1}^{5}\right]\left(1+\alpha \tau_{1}\right) T_{0} } \\
& -\left(\frac{N+M \theta_{0}}{k_{0} P_{0}} k_{1}-\frac{M \theta_{0}}{3 k_{0} P_{0}} k_{1}^{3}\right) w\left(1+\alpha \tau_{1}\right) T_{0} \\
& +\left[\left(N \theta_{1}+M \theta_{1}^{2}\right)-\frac{N \theta_{1}+2 M \theta_{1}^{2}}{3}+\frac{M \theta_{1}^{2}}{5}\right] T_{2} \\
& -\frac{3 N+2 M \theta_{1}}{3 k_{0} P_{0}} T_{2} w-\frac{\beta}{2} \tau_{1}^{2} k_{1}\left(1+\alpha_{1}\right) T_{0}-\frac{\beta}{2} \tau_{2}^{2} T_{2}-C_{x} .
\end{aligned}
$$

We solved the partial derivative on $\tau_{1}$ and $\tau_{2}$, and let $\partial_{L_{s_{2}}} / \partial_{\tau_{1}}=0$, $\partial_{L_{s_{2}}} / \partial_{\tau_{2}}=0$, obtaining the following values:

$$
\begin{aligned}
& \tau_{1}^{*}=\frac{1}{3 \alpha} \sqrt{1+\frac{6 \alpha^{2}\left(A_{3}-A_{4}\right)}{k_{1} \beta}}-\frac{1}{3 \alpha} . \\
& \tau_{2}^{*}=\frac{1}{3 \alpha} \sqrt{1+\frac{6 \alpha^{2}\left(A_{5}-A_{6}\right)}{\beta}}-\frac{1}{3 \alpha} .
\end{aligned}
$$

Thus, the maximum profit under the variable FKE strategy is equal to $L_{s_{2}}{ }^{*}\left(\tau_{1}{ }^{*}, \tau_{2}{ }^{*}\right)$, while the profit in a unit time period is equal to $L_{s_{2}}{ }^{*}\left(\tau_{1}{ }^{*}, \tau_{2}{ }^{*}\right) /\left(T_{1}+T_{2}\right)$, and the average freshness degree of the product under this strategy is the following:

$$
\begin{aligned}
\overline{\theta_{S_{2}}} & =\frac{\left.\int\left(\theta_{0}-\theta_{0}\left(t^{2} / T^{2}\right)\right) d t\right|_{0} ^{T_{1}}+\left.\int\left(\theta_{1}-\left(\theta_{1} / T_{2}^{2}\right) t^{2}\right) d t\right|_{0} ^{T_{2}}}{T_{1}+T_{2}} \\
& =\frac{2}{3} \theta_{0}+\frac{\theta_{0}}{3}\left(\frac{T_{1}-k_{1}^{2} T_{2}}{T_{1}+T_{2}}-k_{1}^{2}\right) .
\end{aligned}
$$

Proposition 4. $\tau_{2}{ }^{*}<\tau^{*}<\tau_{1}{ }^{*}$.

Proof. Since $\theta_{1}<\theta_{0}$, it can be deduced from Proposition 2 that $\tau_{2}{ }^{*}<\tau^{*}$ and $k_{1}<0$. Consequently, $\left(A_{3}-A_{4} / k_{1}\right)>A_{1}-A_{2}$, hence $\tau^{*}<\tau_{1}^{*}$.

Proposition 4 shows that, under the variable effort fresh-keeping strategy, the FKE level required in the first stage is often higher than that required under the fixed effort fresh-keeping strategy, while the FKE level required in the second stage is lower than that under the fixed effort fresh-keeping strategy. In general, the variable effort fresh-keeping strategy raises the maximum FKE, which implies an increasing of the difficulty of fresh-keeping for the retailer. Therefore, the prerequisite for adopting the variable effort fresh-keeping strategy is that the retailer has the ability to input the required level of FKE.

Proposition 5. When the adjustment point $k_{1} T_{1}>$ $\sqrt{1+\left(\left(5\left(N k_{0} P_{0}-\mathrm{MW}\right) / 4 M k_{0} P_{0}\right)-\sqrt{\left(15 \mathrm{NW} / 2 M k_{0} P_{0}\right)+\left[\left(5\left(N k_{0} P_{0}-\mathrm{MW}\right)\right.\right.}\right.}$ $\sqrt{\left.\sqrt{\left.\left(4 M k_{0} P_{0}\right)\right]^{2}} / 2 \theta_{0}\right)} T_{1}$, the determined level of FKE after adjustment is 0 , which means that the best choice is not to make FKE.

When it comes to adjusting the FKE, there is an optimal level of FKE before and after adjustment. The price of the product will continue to decrease as freshness continues to decline; hence, the value of $A_{5}$ will continue to decrease. When $A_{5}-A_{6}<0$, the optimal FKE after adjustment is equal to $\tau_{2}{ }^{*}=(1 / 3 \alpha) \sqrt{1+\left(6 \alpha_{2}{ }^{2}\left(A_{5}-A_{6}\right) / \beta\right)}-(1 / 3 \alpha)<0$. In this case, the optimal FKE level is a negative number, indicating that the best choice is not to make FKE. Therefore, when the freshness of a fresh agricultural product declines to a certain extent, it is no longer necessary to make FKE.

It can be deduced from Proposition 5 that when the first fresh-keeping stage is $T_{1}>\sqrt{1+\left(\left(5\left(N k_{0} P_{0}-\mathrm{MW}\right) / 4 M k_{0} P_{0}\right)\right.}$ $\sqrt{\sqrt{\left.-\left(15 \mathrm{NW} / 2 M k_{0} P_{0}\right)+\left[\left(5\left(N k_{0} P_{0}-\mathrm{MW}\right) / 4 M k_{0} P_{0}\right)\right]^{2} / 2 \theta_{0}\right)}} T_{1}$ $=k_{1}^{\prime} T_{1}$, the required level of FKE in the second stage should be negative (i.e., there is no need to make FKE) to obtain the maximum profit. In other words, no FKE should be made when the product freshness drops below $\theta_{1}^{\prime}=\left(1-k_{1}^{\prime} 2\right) \theta_{0}$, which leads to Proposition 6.

Proposition 6. The entire shelf life of a product should be divided into the fresh-keeping stage and the nonfresh-keeping stage. The fresh-keeping stage period is $\left[\theta_{0}, \theta_{1}^{\prime}\right]$, while the nonfresh-keeping stage is the period when product freshness is lower than $\theta_{1}^{\prime}$.

Proposition 7. The average freshness level of the product under the fixed FKE strategy is a fixed value; the average freshness level of the product under the adjustment FKE strategy is improved, and the degree of freshness improvement is directly proportional to the initial freshness of the product.

4.2. FKE Optimization Model. The basic fresh-keeping model was established on the basis of the assumption that FKE is needed throughout the whole sale process. As indicated by Proposition 6, since the gain generated by the FKE vanishes when the freshness of the fresh agricultural product drops below $\theta_{1}^{\prime}$, FKE should be made only when the product freshness is higher than $\theta_{1}^{\prime}$, regardless of whether the fixed or the variable effort fresh-keeping strategy is used. The two fresh-keeping strategies can be optimized based on this principle. Under the fixed effort fresh-keeping strategy, the fresh-keeping stage is $T_{3}=k_{1}^{\prime}\left(1+\alpha_{3}\right) T_{0}$, where $k_{1}^{\prime}=\sqrt{1-\left(\theta_{1}^{\prime} / \theta_{0}\right)}$. The product freshness drops to $\theta_{1}^{\prime}$ exactly at the end of the fresh-keeping 
stage, and the rest stretch of time is the nonfresh-keeping stage $T_{4}=k_{4} T_{0}$, where $k_{4}=\left(1-\sqrt{1-\left(\theta_{1} / \theta_{0}\right)}\right)$. Under the variable effort fresh-keeping strategy, the two freshkeeping stages are $T_{5}=k_{2}\left(1+\alpha \tau_{5}\right) T_{0}$ and $T_{6}=k_{3}\left(1+\alpha \tau_{6}\right) T_{0}$ respectively, where $k_{2}=\sqrt{1-\left(\theta_{2} / \theta_{0}\right)}, k_{3}=\sqrt{1-\left(\theta_{1}^{\prime} / \theta_{2}\right)}, \theta_{2}$ is the FKE adjustment point. The product freshness drops to $\theta_{1}^{\prime}$ exactly at the end of the first fresh-keeping stage, and the rest stretch of time is nonfresh-keeping stage $T_{4}=k_{4} T_{0}$. The basic model is optimized based on this stage division.

\subsubsection{Optimization of the Fixed Effort Fresh-Keeping Strategy}

(1) The fresh-keeping stage $T_{3}=k_{1}^{\prime}\left(1+\alpha \tau_{3}\right) T_{0}$. The sales income is the following: $\int_{0}^{T 3} D_{t} P_{t} d_{t}=$ $\left(N \theta_{0}+M \theta_{0}^{2}\right) t-\left(N \theta_{0}+2 M \theta_{0}^{2} / 3\left(1+\alpha \tau_{3}\right)^{2} T_{0}^{2}\right) t^{3}+\left(M \theta_{0}^{2} / 5\right.$ $\left.\left(1+\alpha \tau_{3}\right)^{4} T_{0}^{4}\right)\left.t^{5}\right|_{0} ^{T_{3}}=\left[\left(N \theta_{0}+M \theta_{0}^{2}\right) k_{1}^{\prime}-\left(N \theta_{0}+2 M \theta_{0}^{2} / 3\right) k_{1}^{\prime 3}\right.$ $\left.+\left(M \theta_{0}^{2} / 5\right) k_{1}^{\prime 5}\right]\left(1+\alpha_{3} \tau_{3}\right) T_{0}=A_{7}\left(1+\alpha \tau_{3}\right) T_{0}$ The sales volume is the following:

$\int_{0}^{T 3} D_{(t)} d_{t}=\left(N+M \theta_{0} / k_{0} P_{0}\right) t-\left(M \theta_{0} 3 k_{0} P_{0}\left(1+\alpha \tau_{3}\right)^{2} T_{0}^{2}\right)$ $\left.t^{3}\right|_{0} ^{T_{3}}=\left(\left(N+M \theta_{0} / k_{0} P_{0}\right) k_{1}^{\prime}-\left(M \theta_{0} / 3 k_{0} P_{0}\right) k_{1}^{\prime 3}\right)\left(1+\alpha \tau_{3}\right) T_{0}$, while the purchase cost is $\left(\left(N+M \theta_{0} / k_{0} P_{0}\right) k_{1}^{\prime}-\right.$ $\left.\left(M \theta_{0} / 3 k_{0} P_{0}\right) k_{1}^{\prime 3}\right) w\left(1+\alpha \tau_{3}\right) T_{0}=A_{8}\left(1+\alpha \tau_{3}\right) T_{0}$ and the FKC is $(\beta / 2) \tau_{3}^{2} k_{1}^{\prime}\left(1+\alpha \tau_{3}\right) T_{0}$.

(2) Nonfresh-keeping stage $T_{4}=\left(1-\sqrt{1-\left(\theta_{1} / \theta_{0}\right)}\right) T_{0}=k_{4} T_{0}$. The sales income is: $\int_{0}^{T_{t}} D_{t} P_{t} d_{t}=\left(N \theta_{1}^{\prime}+M \theta_{1}^{\prime 2}\right) t-\left(N \theta_{1}^{\prime}+2 M \theta_{1}^{\prime 2}\right.$ $\left./ 3 T_{4}^{2}\right) t^{3}+\left.\left(M \theta_{1}^{\prime 2} / 5 T_{4}^{4}\right) t^{5}\right|_{0} ^{T_{4}}=\left[\left(N \theta_{1}+M \theta_{1}^{2}\right) k_{4}-\right.$ $\left.\left(N \theta_{1}+2 M \theta_{1}{ }^{2} / 3\right) k_{4}{ }^{3}+\left(\mathrm{M} \theta_{1}{ }^{2} / 5\right) k_{4}{ }^{5}\right] T_{0}=A_{9} T_{0}$, while the sales volume is $\int_{0}^{T_{4}} D_{(t)} d_{t}=\left(N+M \theta_{1} / k_{0} P_{0}\right) t-$ $\left.\left(M \theta_{1} / 3 k_{0} P_{0} T_{4}^{2}\right) t^{3}\right|_{0} ^{T_{4}}=\left(\left(N+M \theta_{1} / k_{0} P_{0}\right) k_{4}-\left(M \theta_{1} / 3 k_{0} P_{0}\right) k_{4}^{3}\right) T_{0}$, and the purchase cost is $\left(\left(N+M \theta_{1} / k_{0} P_{0}\right) k_{4}-\right.$ $\left.\left(M \theta_{1} / 3 k_{0} P_{0}\right) k_{4}^{3}\right) w T_{0}=A_{10} T_{0}$.

Thus, the total profit under the optimized fixed effort fresh-keeping strategy is the following: $L_{S_{3}}=\left(A_{7}-A_{8}\right)$ $\left(1+\alpha \tau_{3}\right) T_{0}-(\beta / 2) \tau_{3}^{2} k_{1}^{\prime}\left(1+\alpha \tau_{3}\right) T_{0}+\left(A_{9}-A_{10}\right) T_{0}-C_{X}$. The optimal FKE was calculated as $\tau_{3}^{*}=(1 / 3 \alpha)$ $\sqrt{1+\left(6 \alpha^{2}\left(A_{7}-A_{8}\right) / k_{1}^{\prime} \beta\right)}-(1 / 3 \alpha)$; the profit under the optimized fixed effort fresh-keeping strategy is $L_{S_{3}}{ }^{*}$, while the profit in a unit time period is $L_{S_{3}}{ }^{*} /\left(T_{3}+T_{4}\right)$, and the average product freshness degree under this strategy is the following:

$$
\begin{aligned}
\overline{\theta_{S_{3}}} & =\frac{\left.\int\left(\theta_{0}-\theta_{0}\left(t^{2} / T^{2}\right)\right) d t\right|_{0} ^{T_{3}}+\left.\int\left(\theta_{1}-\left(\theta_{1} / T_{2}^{2}\right) t^{2}\right) d t\right|_{0} ^{T_{4}}}{T_{3}+T_{4}} \\
& =\frac{2}{3} \theta_{0}+\frac{\theta_{0}}{3}\left(\frac{T_{3}-k_{1}^{\prime 2} T_{4}}{T_{3}+T_{4}}-k_{1}^{\prime 2}\right) .
\end{aligned}
$$

4.2.2. Optimization of the Variable Effort Fresh-Keeping Strategy

(1) The first fresh-keeping stage $T_{5}=k_{2}\left(1+\alpha \tau_{5}\right) T_{0}$.

The sales income is the following: $\int_{0}^{T_{5}} D_{t} P_{t} d_{t}=\left[\left(N \theta_{0}+\right.\right.$ $\left.\left.M \theta_{0}^{2}\right) k_{2}-\left(N \theta_{0}+2 M_{0}^{2} / 3\right) k_{2}^{3}+\left(M_{0}^{2} / 5\right) k_{2}^{5}\right]\left(1+\alpha \tau_{5}\right) T_{0}$ $=A_{11}\left(1+\alpha \tau_{5}\right) T_{0}$. The sales volume is: $\int_{0}^{T_{5}} D_{(t)} d_{t}=$ $\left(N+M \theta_{0} / k_{0} P_{0}\right) t-\left.\left(M \theta_{0} / 3 k_{0} P_{0}\left(1+\alpha \tau_{5}\right)^{2} T_{0}^{2}\right) t^{3}\right|_{0} ^{T_{5}}$ $=\left(\left(N+M \theta_{0} / k_{0} P_{0}\right) k_{2}-\left(M \theta_{0} / 3 k_{0} P_{0}\right) k_{2}^{3}\right)\left(1+\alpha \tau_{5}\right) T_{0}$, the purchase cost is $\left(\left(N+M \theta_{0} / k_{0} P_{0}\right) k_{2}-\left(M \theta_{0} / 3 k_{0} P_{0}\right)\right.$ $\left.k_{2}^{3}\right) w\left(1+\alpha \tau_{5}\right) T_{0}=A_{12}\left(1+\alpha \tau_{5}\right) T_{0}$, and the FKC is $(\beta / 2) \tau_{5}^{2} k_{2}\left(1+\alpha \tau_{5}\right) T_{0}$.

(2) The second fresh-keeping stage $T_{6}=k_{3}\left(1+\alpha \tau_{6}\right) T_{0}$. The sales income is: $\int_{0}^{T_{6}} D_{(t)} d_{t}=\left[\left(N \theta_{2}+M \theta_{2}^{2}\right) k_{3}-\left(N \theta_{2}+\right.\right.$ $\left.\left.2 M \theta_{2}{ }^{2} / 3\right) k_{3}{ }^{3}+\left(M \theta_{2}{ }^{2} / 5\right) k_{3}{ }^{5}\right]\left(1+\alpha \tau_{6}\right) T_{0}=A_{13}\left(1+\alpha \tau_{6}\right) T_{0}$. The sales volume is: $\int_{0}^{T_{6}} D_{(t)} d_{t}=\left(N+M \theta_{2} / k_{0} P_{0}\right) t-$ $\left.\left(M \theta_{2} / 3 k_{0} P_{0}\left(1+\alpha_{6} \tau_{6}\right)^{2} T_{0}{ }^{2}\right) t^{3}\right|_{0} ^{T_{6}}=\left(\left(N+M \theta_{2} / k_{0} P_{0}\right) k_{3}\right.$ $\left.-\left(M \theta_{2} / 3 k_{0} P_{0}\right) k_{3}{ }^{3}\right)\left(1+\alpha \tau_{6}\right) T_{0}$, the purchase cost is $\left(\left(N+M \theta_{2} / k_{0} P_{0}\right) k_{3}-\left(M \theta_{2} / 3 k_{0} P_{0}\right) k_{3}^{3}\right)\left(1+\alpha \tau_{6}\right) w T_{0}$ $=A_{14}\left(1+\alpha \tau_{6}\right) T_{0}$, and the FKC is $(\beta / 2) \alpha^{2} k_{3}\left(1+\alpha \tau_{6}\right) T_{0}$.

(3) Nonfresh-keeping stage $T_{4}=\left(1-\sqrt{1-\theta_{1} / \theta_{0}}\right) T_{0}=k_{4} T_{0}$. $A_{9} T_{0}$ is the sales income, and $A_{10} T_{0}$ is the purchase cost. Thus, the total profit under the optimized variable effort fresh-keeping strategy was calculated in the following way:

$L_{S_{4}}=\left(A_{11}-A_{12}\right)\left(1+\alpha \tau_{5}\right) T_{0}-(\beta / 2) \tau_{5}^{2} k_{2}\left(1+\alpha \tau_{5}\right) T_{0}+$ $\left(A_{13}-A_{14}\right)\left(1+\alpha \tau_{6}\right) T_{0}-(\beta / 2) \tau_{6}^{2} k_{3}\left(1+\alpha \tau_{6}\right) T_{0}+\left(A_{9}-\right.$ $\left.A_{9}\right) T_{0}-C_{X}$. The maximum FKE was calculated as $\tau_{5}^{*}=(1 / 3 \alpha) \sqrt{1+\left(6 \alpha^{2}\left(A_{11}-A_{12}\right) / k_{2} \beta\right)}-(1 / 3 \alpha)$, $\tau_{6}^{*}=(1 / 3 \alpha) \sqrt{1+\left(6 \alpha^{2}\left(A_{13}-A_{14}\right) / k_{2} \beta\right)}-(1 / 3 \alpha)$, the maximum profit is $L_{S_{4}}{ }^{*}\left(\tau_{5}^{*}, \tau_{6}^{*}\right)$, the profit in a unit time period is $L_{S_{4}}{ }^{*}\left(\tau_{5}^{*}, \tau_{6}^{*}\right) / T_{5}+T_{6}+T_{4}$, and the average product freshness degree under this strategy is the following:

$$
\begin{aligned}
\overline{\theta_{S_{4}}} & =\frac{\left.\int\left(\theta_{0}-\theta_{0}\left(t^{2} /\left(1+\alpha_{5} \tau_{5}\right)^{2} T_{0}^{2}\right)\right) d t\right|_{0} ^{T_{5}}+\left.\int\left(\theta_{2}-\theta_{2}\left(t^{2} /\left(1+\alpha_{6} \tau_{6}\right)^{2} T_{0}^{2}\right)\right) d t\right|_{0} ^{T_{6}}+\left.\int\left(\theta_{1}-\left(\theta_{1} / T_{2}^{2}\right) t^{2}\right) d t\right|_{0} ^{T_{4}}}{T_{5}+T_{6}+T_{4}} \\
& =\theta_{0}+\frac{1}{T_{5}+T_{6}+T_{4}}\left(\left(k_{2}^{2} k_{3}^{2}-k_{2}^{2}-k_{3}^{2}\right) \theta_{0} T_{4}-\frac{k_{4}^{2}}{3}\left(1-k_{2}^{2}-k_{3}^{2}+k_{2}^{2} k_{3}^{2}\right) T_{4}-\theta_{0} k_{3}^{2} T_{6}-\frac{\theta_{0} k_{3}^{2}}{3}\left(1-k_{2}^{2}\right) T_{6}-\frac{\theta_{0} k_{2}^{2}}{3} T_{5}\right)
\end{aligned}
$$

Proposition 8. If two batches of the same agricultural product with the same initial freshness level are preserved using the fixed and variable effort fresh-keeping strategies separately, then $\tau_{3}{ }^{*}>\tau^{*}, \tau_{5}{ }^{*}>\tau_{1}{ }^{*}$.
Proof. $\left(\left(A_{7}-A_{8}\right) / k_{1}^{\prime}\right)-\left(A_{1}-A_{2}\right)=\left[\left(N \theta_{0}+M \theta_{0}{ }^{2}\right)-\left(N \theta_{0}+2 M \theta_{0}{ }^{2} / 3\right) k_{1}^{\prime 2}\right.$ $\left.+\left(M \theta_{0}{ }^{2} / 5\right) k_{1}^{\prime 4}\right]-\left(\left(\left(N+M \theta_{0}\right) / k_{0} P_{0}\right)-\left(M \theta_{0} / 3 k_{0} P_{0}\right) k_{1}^{\prime 2}\right) w-$ $\left(\left(N \theta_{0}+M \theta_{0}{ }^{2}\right)-\left(\left(N \theta_{0}+2 M \theta_{0}{ }^{2}\right) / 3\right)+\left(M \theta_{0}{ }^{2} / 5\right)-\left(\left(N+M \theta_{0} / k P_{0}\right)\right.\right.$ 
TABle 2: Parameter set.

\begin{tabular}{lc}
\hline Symbol & Definition \\
\hline$P_{0}$ & The selling price of the freshest product \\
$P_{t}$ & The time-varying selling price of a product \\
$D_{t}$ & Real-time market demand \\
$C_{X}$ & Extra cost associated with each order (e.g., transport \\
$k_{0}$ & fee, handling fee) \\
$Q$ & Price adjustment coefficient related to freshness \\
$R$ & Sales volume of a product \\
$L$ & Sales income of a product \\
$w$ & Sales profit of the retailer \\
$\tau$ & Level of fresh-keeping effort \\
$C$ & Fresh-keeping cost (FKC) \\
$T_{0}$ & Shelf life of a product with an initial freshness degree \\
$\theta_{0}$ & of $\theta_{0}$ with no fresh-keeping measures in place \\
$T$ & Initial freshness of a product, $\theta_{0} \in$ [0, 1]
\end{tabular}

$\left.\left.\left(M \theta_{0} / 3 k P_{0} T^{2}\right)\right) w\right)=\left(1-{k_{1}^{\prime 2}}^{2}\right)\left(N \theta_{0}+2 M \theta_{0}^{2} / 3\right)+\left(M \theta_{0}^{2} / 5\right)$ $\left(k_{1}^{\prime 4}-1\right)+\left(M \theta_{0} / 3 k_{0} P_{0}\right)\left(k_{1}^{\prime 2}-1\right)$. It can be deduced from Eq. (4) that $U_{0}-a P_{t}+b \theta_{t}>0$.Consequently, $N>M$, and $0<k_{1}^{\prime}<1$, thus $\left(A_{7}-A_{8} / k_{1}^{\prime}\right)-\left(A_{1}-A_{2}\right)>0$. When the agricultural products have the same initial freshness, they have the same $\alpha$, thus $\tau_{3}{ }^{*}>\tau^{*}$ is proved. $\tau_{5}{ }^{*}>\tau_{1}{ }^{*}$ can be provwwed in the same way.

Proposition 8 indicates that the optimization of both the fixed fresh-keeping strategy and the variable fresh-keeping strategy require retailers to enhance their FKE, thus increasing the difficulty of fresh-keeping for the retailers.

\section{Numerical Results}

A retailing dataset of one fresh agricultural product was used to verify the model and the aforementioned findings. The relevant parameter settings are as illustrated in Table 2.

(1) Basic FKE model

Tables 3 and 4 show the effects of retailer's FKE level $\tau$ on product sales, profit, and average freshness under the basic fixed effort fresh-keeping strategy and the variable effort fresh-keeping strategy.
TABle 3: Product sales and average freshness under basic fixed FKE.

\begin{tabular}{lccccc}
\hline$\tau$ & $R_{T}$ & $Q_{T}$ & $L_{S_{1}}$ & $L_{S_{1}} / T_{0}$ & $\overline{\theta_{S_{1}}}$ \\
\hline 0 & 1831.8 & 476.4 & 479 & 68.4 & 0.63 \\
0.1 & 2005.8 & 521.6 & 557.2 & 72.7 & 0.63 \\
0.2 & 2179.8 & 566.9 & 622.7 & 74.8 & 0.63 \\
0.3 & 2353.8 & 612.1 & 672.9 & 74.8 & 0.63 \\
0.4 & 2527.9 & 657.4 & 704.9 & 73.0 & 0.63 \\
0.5 & 2701.9 & 702.7 & 715.9 & 69.3 & 0.63 \\
0.6 & 2875.9 & 747.9 & 703.1 & 64.0 & 0.63 \\
0.7 & 3049.9 & 793.2 & 663.8 & 57.0 & 0.63 \\
0.8 & 3223.9 & 838.4 & 595.2 & 48.3 & 0.63 \\
0.9 & 3398 & 883.7 & 494.4 & 38.1 & 0.63 \\
0.95 & 3485 & 906.3 & 431 & 32.4 & 0.63 \\
\hline
\end{tabular}

TABLE 4: Product sales and average freshness under basic variable FKE.

\begin{tabular}{lccccccc}
\hline$k_{1}$ & $\tau_{1}{ }^{*}$ & $\tau_{2}{ }^{*}$ & $R_{T}$ & $Q_{T}$ & $L_{S_{2}}$ & $L_{S_{2}} / T_{1}+T_{2}$ & $\overline{\theta_{S_{2}}}$ \\
\hline 0 & 0 & 0.5 & 2698.92 & 701.88 & 715.89 & 69.4 & 0.63 \\
0.1 & 0.81 & 0.49 & 3138.3 & 784.85 & 950.47 & 82.6 & 0.66 \\
0.2 & 0.8 & 0.46 & 3459.21 & 858.96 & 1119.76 & 89.0 & 0.67 \\
0.3 & 0.79 & 0.41 & 3660.92 & 922.78 & 1216.85 & 90.1 & 0.67 \\
0.4 & 0.77 & 0.34 & 3751.79 & 974.35 & 1237.69 & 86.6 & 0.66 \\
0.5 & 0.74 & 0.24 & 3747.89 & 1010.72 & 1181.78 & 79.6 & 0.63 \\
0.6 & 0.71 & 0.12 & 3177.59 & 785.5 & 951.65 & 82.8 & 0.67 \\
0.7 & 0.67 & 0 & 3104.44 & 789.13 & 876.22 & 75.7 & 0.65 \\
0.8 & 0.62 & 0 & 2982.47 & 777.04 & 788.9 & 69.1 & 0.63 \\
0.9 & 0.56 & 0 & 2837.23 & 748.32 & 725.14 & 65.9 & 0.62 \\
1 & 0.5 & 0 & 2698.92 & 701.88 & 715.89 & 69.4 & 0.63 \\
\hline
\end{tabular}

Table 3 shows that the sales profit is 479.0 when $\tau^{*}=\tau=0.5$, and the sales volume and sales income are 476.4 and 1831.8, respectively. As the retailer inputs more effort on fresh-keeping, the sales income, the sales volume, and the FKC increase constantly. The profit in the sales cycle reaches the maximum value when the FKE is $\tau^{*}=\tau=0.5$. When the FKE $\tau>0.5$, the profit is lessened, thus proving Propositions 1 and 3. The fact that $\overline{\theta_{S_{1}}}=0.63 \mathrm{demonstrates}$ that adopting the fixed effort fresh-keeping strategy in one sales cycle will not improve the average freshness of the product. In general, while a moderate increase in the FKE can increase profit, overly high FKE level would incur a loss of profit.

Table 4 shows that the optimal FKE levels in the two stages drop constantly as $k_{1}$ increases. When implementing the variable effort fresh-keeping strategy, the retailer can reduce the level of FKE by adjusting $k_{1}$. When $k_{1}$ exceeds 0.7 , the optimal FKE in the second stage is 0 , thus validating Proposition 5. As $k_{1}$ increases, the initial freshness $\theta_{1}=\theta_{0}\left(1-k_{1}^{2}\right)$ of the second fresh-keeping stage drops constantly, and the optimal FKE level $\tau_{2}^{*}$ also drops gradually, thus validating Proposition 2 .

With regard to profit, $\tau_{1}^{*}$ and $\tau_{2}^{*}$ drop constantly with the increase of $k_{1}$; the sales income and the sales volume reach their peaks when $k_{1} \approx 0.4$, and the maximum profit obtained by the retailer is 1210.03 . As $k_{1}$ increases further, the sales 
TABle 5: Product sales and average freshness under optimized fixed FKE.

\begin{tabular}{lccccc}
\hline$\tau_{3}$ & $R_{T}$ & $Q_{T}$ & $L_{S_{1}}$ & $L_{S_{1}} / T$ & $\overline{\theta_{S_{1}}}$ \\
\hline 0.1 & 2042.33 & 509.43 & 619.72 & 83.01 & 0.66 \\
0.2 & 2196.05 & 541.59 & 696.55 & 87.83 & 0.67 \\
0.3 & 2349.76 & 573.75 & 762.6 & 90.82 & 0.68 \\
0.4 & 2503.48 & 605.91 & 815.93 & 92.07 & 0.68 \\
0.5 & 2657.19 & 638.07 & 854.58 & 91.62 & 0.69 \\
0.6 & 2810.91 & 670.23 & 876.59 & 89.51 & 0.69 \\
0.67 & 2915.05 & 692.01 & 881.06 & 87.16 & 0.7 \\
0.7 & 2964.62 & 702.39 & 880.01 & 85.78 & 0.7 \\
0.8 & 3118.34 & 734.55 & 862.89 & 80.46 & 0.7 \\
0.9 & 3272.05 & 766.71 & 823.27 & 73.58 & 0.71 \\
1 & 3425.77 & 798.87 & 759.19 & 65.14 & 0.71 \\
\hline
\end{tabular}

TABle 6: Parameter set.

\begin{tabular}{cccccccccccc}
\hline$k_{0}$ & $\lambda$ & $U_{0}$ & $a$ & $b$ & $\beta$ & $C_{x}$ & $\theta_{0}$ & $w$ & $\theta_{0}$ & $T_{0}$ & $\alpha$ \\
1.00 & 80 & 0.8 & 0.02 & 0.2 & 140 & 400 & 0.95 & 2 & 6 & 7 & 0.95 \\
\hline
\end{tabular}

TABLE 7: Product sales and average freshness under optimized variable FKE.

\begin{tabular}{lccccccc}
\hline$k_{2}$ & $\tau_{5}{ }^{*}$ & $\tau_{6}{ }^{*}$ & $R_{T}$ & $Q_{T}$ & $L_{S_{2}}$ & $L_{S_{2}} / T_{1}+T_{2}$ & $\overline{\theta_{S_{2}}}$ \\
\hline 0 & 0 & 0.67 & 2915.0 & 692.0 & 881.1 & 87.2 & 0.73 \\
0.1 & 0.81 & 0.66 & 3362.0 & 773.6 & 1114.8 & 98.9 & 0.75 \\
0.2 & 0.8 & 0.64 & 3701.6 & 843.2 & 1281.7 & 104.4 & 0.75 \\
0.3 & 0.79 & 0.61 & 3921.3 & 898.7 & 1374.7 & 105.0 & 0.75 \\
0.4 & 0.77 & 0.56 & 4009.6 & 936.4 & 1389.5 & 101.7 & 0.73 \\
0.42 & 0.76 & 0.55 & 4010.4 & 941.4 & 1383.0 & 100.7 & 0.73 \\
0.45 & 0.76 & 0.53 & 4000.6 & 946.8 & 1367.2 & 98.9 & 0.72 \\
0.5 & 0.74 & 0.49 & 3953.3 & 949.7 & 1325.2 & 95.5 & 0.71 \\
0.6 & 0.71 & 0.41 & 3723.4 & 921.8 & 1182.7 & 87.6 & 0.69 \\
0.63 & 0.7 & 0.38 & 3606.5 & 898.3 & 1124.0 & 85.4 & 0.69 \\
0.65 & 0.69 & 0.35 & 3507.9 & 875.2 & 1079.6 & 84.2 & 0.69 \\
0.68 & 0.68 & 0.32 & 3300.1 & 818.1 & 999.0 & 83.4 & 0.69 \\
0.7 & 0.67 & 0.00 & 2915.0 & 692.0 & 881.1 & 87.2 & 0.73 \\
\hline
\end{tabular}

income and the sales volume decrease gradually. The fresh-keeping strategy becomes the fixed effort fresh-keeping strategy when $k_{1}=1, \tau_{1}^{*}=\tau^{*}=0.5$, and the profit drops to 715.89. With regard to freshness, the freshness degree reaches the highest value of 0.67 when $k_{1}$ is $0.2,0.3$, and 0.6 ; the profit reaches its peak when $k_{1}=0.4$, and the average freshness degree still reaches 0.66 , a value which is higher than 0.63 , attained under the fixed effort fresh-keeping strategy. In summary, the sales profit and the average freshness degree of the product can be improved effectively by adjusting the FKE level, even though the highest average freshness degree does not necessary coincide with the maximum profit.

\section{(2) Optimized FKE model}

Table 5 shows the effect of the improved fixed effort fresh-keeping strategy. It can be seen that the sales income and the sales volume of the product increase gradually with the increase of $\tau_{3}=0.67=\tau_{3}{ }^{*}$. The maximum profit of 881.06 is obtained when $\tau_{3}=0.67=\tau_{3}{ }^{*}$. A comparison with Table 6 reveals that under the condition of inputting the same amount of effort, the optimized fixed effort fresh-keeping strategy yields the largest profit, improving the maximum profit and the minimum profit from 715.9 and 431.0 , to 876.59 and 619.72 , respectively. The optimal FKE corresponding to the maximum profit increases from $\tau^{*}=0.5$ to $\tau_{3}{ }^{*}=0.67$. This indicates that the optimized fixed effort fresh-keeping strategy requires a higher level of FKE, which increases the difficulty of fresh-keeping for the retailer, thus validating Proposition 7. A comparison of the freshness degree figures reveals that the optimized strategy can significantly improve the average freshness degree of the product. In general, the optimized fixed effort fresh-keeping strategy can improve both the profit and the freshness of the product; however, it requires a higher level of FKE, thus increasing the difficulty of fresh-keeping for retailers.

Table 7 shows the effect of the improved variable effort fresh-keeping strategy. It can be seen that $\tau_{5}^{*}$ and $\tau_{6}^{*}$ drop constantly with the increase in $k_{2}$; the sales income and sales volume reach their peaks when $k_{2} \approx 0.4$, and the maximum profit obtained by the retailer is 1343.47. The optimal FKE levels of the two stages are 0.77 and 0.52 , respectively; these values are not significantly higher than the FKE level required by the basic strategy (i.e., the difficulty of fresh-keeping does not increase). With regard to freshness, the product freshness degree reaches the maximum value when $k_{2}$ is adjusted to $k_{2}=0.2$, and the average freshness degree decreases gradually with the increase of $k_{2}$. This can be explained in the following way. As $k_{2}$ increases, the FKE level in the first stage must be lowered in order to maximize the profit. Consequently, the highly fresh agricultural products are not preserved with the appropriate level of FKE in the first stage, which accelerates the drop of freshness degree in the first stage, thus dragging down the average freshness degree. A comparison with Table 3 reveals that the optimized variable effort fresh-keeping strategy achieves a higher average freshness degree and a significantly higher sales profit than the basic version. In general, the optimized variable effort fresh-keeping strategy can effectively improve the sales profit and the average freshness degree, without increasing the difficulty of fresh-keeping.

Comparing the values in Tables 3-5 and 7, it can be seen that the optimal FKE level that maximizes the profit of the product and maximizes the freshness is not equal. Compared with nonpreservative products, the level of FKE that can increase the average freshness can increase the profit of retailers. And when the profit of the product is increased, the FKE level may not increase the average freshness degree of the product (as shown in Table 3, $k_{1}=0.9$ ). Retailers should pay more attention to the impact on the environment in the process of agricultural product sales. Because the impact of profit increase on average freshness is uncertain, when retailers want to reduce their environmental impact, average freshness should be used as the main reference.

\section{Conclusion}

As perishable products, agri-products' freshness will continue to decrease after harvesting, which will not only affect the sales 
volume and price, but also reduce the profit of the retailers. And it will cause more greenhouse gas emissions and pollute the environment. This paper is a preliminary study aimed at providing application of FKE investment for retailers in the fresh-product model. In the current paper, a supplier-buyer structure in an FSC system was modeled under two approaches: (1) The fixed FKE model. (2) The variable FKE model. We proposed a framework to optimize the FKE in two approaches under multifactor-sensitive demand where the products have a limited life. The paper also explores the difference in profit and freshness between two approaches. To verify the proposed model in practice, different levels of FKE from a real-life case study were examined.

Therefore, this paper establishes models of freshness and sales profit and proposes different FKE strategies. Comparing the difference between profit and freshness, the following conclusions are obtained.

(1) Under the different FKE strategies, there is always an optimal level of FKE, and the maximum profit can be obtained.

(2) Under the fixed FKE strategy, the optimal FKE level is directly proportional to the initial freshness of the product.The higher initial freshness is, the retailer should invest the higher FKE. When the initial freshness is low, the retailer should reduce the FKE level, which is more conducive to the retailer to get the maximum profit.

(3) FKE can increase retailer profits, however, due to the restriction of fresh-keeping cost, the retailer's FKE should be controlled within a reasonable range of $0<\tau<(1 / 2 \alpha) \sqrt{1+\left(8 \alpha^{2}\left(A_{1}-A_{2}\right) / \beta\right)}-(1 / 2 \alpha)$. In the meantime, when the FKE exceeds this value $\tau>(1 / 2 \alpha) \sqrt{1+\left(8 \alpha^{2}\left(A_{1}-A_{2}\right) / \beta\right)}-(1 / 2 \alpha)$, the profits will decrease due to the excessive fresh-keeping cost.

(4) The fixed FKE will not increase the average freshness of fresh produce in a sales cycle, and the adjusted FKE can effectively improve the average freshness. When the freshness of the product is below threshold $\theta_{1}^{\prime}$, the retailer should stop the the FKE. The threshold is related to the purchase price of the product, the selling price, the initial freshness of the product, the sensitivity of the consumer to the price and freshness, and the market demand.

(5) The initial freshness of the product affects the effect of fresh-keeping efforts. The product with high initial freshness is more effective in improving the average freshness degree under the same level of FKE.

When the average freshness is improved, the retailer's profit will also be improved; but when the sales profit is increased, the change of the average freshness is uncertain. Therefore, when retail companies only pay attention to profit changes, the impact of their fresh-keeping strategies on average freshness is uncertain. Even if sales profits are improved, it may lead to a decline in average freshness and increase environmental impact.When retailers pay attention to the average freshness for FKEs, their FKE strategy will play a positive role in retailers'profits.In summary, when retailers are investing in FKE, they should appropriately adjust the level of FKE according to changes in product freshness and market demand. The variable FKE strategy can not only effectively improve the retailer's profit but also effectively improve the average freshness level of fresh agricultural products in the sales cycle, effectively reducing the loss of quality of agricultural products in transportation activities, and is an important means to realize green transportation of agricultural products. When carrying out FKE, due to the constraints of fresh-keeping costs, the level of retailer's FKE should be controlled within a reasonable range of $0<\tau<(1 / 2 \alpha) \sqrt{1+\left(8 \alpha^{2}\left(A_{1}-A_{2}\right) / \beta\right)}-(1 / 2 \alpha)$, when the fresh effort level exceeds this value, the profits will reduce due to the excessive cost. In the process of sales, retailers should pay attention to changes in product freshness. When the freshness falls below the threshold value $\theta_{1}^{\prime}$, the retailer should stop investing in the FKE, because the additional profit generated by the FKE is lower than the cost of fresh-keeping efforts. In addition, retailers should pay more attention to the impact on the environment in the process of agricultural product sales. Since the impact of profit increases on average freshness is uncertain, when retailers want to reduce the impact on the environment, the average freshness should be used as the main reference.

The main managerial implications obtained in this paper can be summarized as follows.

(1) Effectively controlling the decline of freshness of FAP not only meets the demand of consumers for high-quality FAP but also reduces the emission of harmful gases and avoids the waste of agricultural resources. It is clear that the sales profit and the average freshness degree of the product can be improved effectively by adjusting the FKE level. Due to the limitation of fresh-keeping cost, retailers should control their FKE within a certain range in order to maximize profits. Therefore, it is of significance for retailers to formulate appropriate investment strategy and determine the adjustment point of FKE investment.

(2) The results show that by optimizing variable effort fresh-keeping strategy, the sales profit and the average freshness degree can be effectively improved, without increasing the difficulty of fresh-keeping. Nevertheless, several important parameters have a more significant impact on the decision-making process. Consequently, mutiple parameters should be taken into consideration in the decision-making process for retailers.

(3) From a managerial viewpoint, the trends of numerical examples and their findings help retailers to accurately adjust the FKE point in the variable FKE strategy, which is an interesting advantage of the proposed models.

This paper discusses the FKE strategies only from the perspective of retailers, and does not consider the fresh-keeping cooperation and coordination between the upstream and downstream entities in the supply chain; only chieving this goal requires further communication and coordination among the various entities in the supply chain.In the future, the focus of research will be on the fresh-keeping cooperation and 
coordination among supply chain members. And this paper only divides two fresh-keeping stages; however, the freshness is always changing. In the future, real-time FKE adjustment can be achieved through sensors, and more scientific and rational FKE decisions should be made.

\section{Data Availability}

All Data are in this paper.

\section{Conflicts of Interest}

The authors have declared that no competing interests exist.

\section{Acknowledgments}

This paper is supported by the Project of Social Sciences of Beijing (No. 17GLB032) and the Key Project of Beijing Wuzi University (No. 2018XJZD04) in China.

\section{References}

[1] X. Gong and L. B. Jing, "Review on the development of green logistics theory and policy," Modern Economic Research, vol. 11, pp. 126-132, 2017.

[2] M. Yi and X. M. Cheng, "Study on the green innovation strategy of enterprise from the perspective of carbon," Soft Science, vol. 32, no. 7, pp. 74-78, 2018.

[3] J. Chen and B. Dan, "Fresh agricultural product supply chain coordination under the physical loss-controlling," Systems Engineering-Theory \& Practice, vol. 29, no. 3, pp. 54-62, 2009.

[4] M. M. Aung and Y. S. Chang, "Temperature management for the quality assurance of a perishable food supply chain," Food Control, vol. 40, no. 1, pp. 198-207, 2014.

[5] J. Chen and B. Dan, "Ordering policy of fresh agricultural product under circulative loss-controlling," Industrial Engineering and Management, vol. 15, no. 2, pp. 50-55, 2010.

[6] X. Q. Cai, J. Chen, Y. Xiao, and X. Xu, "Optimization and coordination of fresh product supply chains with freshnesskeeping effort," Production and Operations Management, vol. 19, no. 3, pp. 261-278, 2010.

[7] Y. Cao, Y. M. Li, and G. Y. Wan, "Study on fresh degree incentive mechanism of fresh agricultural product supply chain based on consumer utility," Chinese Journal of Management Science, vol. 26, no. 2, pp. 160-174, 2018.

[8] Y. Q. Liu, Y. M. Liu, and G. J. Zhu, "Research on fresh products dual-channel coordination contract in retailer dominated supply chain," Soft Science, vol. 30, no. 8, pp. 123-128+144, 2016.

[9] L. Lin, S. P. Yang, and B. Dan, "Three-level supply chain coordination of fresh and live agricultural products by revenuesharing contracts," Journal of Systems Engineering, vol. 25, no. 4, pp. 484-491, 2010 .

[10] L. Wang and B. Dan, "The incentive mechanism for preservation in fresh agricultural supply chain considering consumer utility," Journal of Industrial Engineering and Engineering Management, vol. 29, no. 1, pp. 200-206, 2015.

[11] X. L. Ma, S. Y. Wang, and H. Jin, "Coordination and optimization of three-echelon agricultural product supply chain considering fresh-keeping effort and quantity/quality elasticity," Chinese Journal of Management Science, vol. 26, no. 2, pp. 175-185, 2018.

[12] Q. Zhang and X. Zhang, "Coordination of fresh agricultural supply chain considering fairness concerns under controlling the loss by freshness-keeping," Chinese Journal of Systems Science, vol. 25, no. 3, pp. 112-116, 2017.

[13] Y. Feng, Y. L. Yu, and Y.Z. Zhang, "Coordination in a three-echelon supply chain of fresh agri-products with TPLSP's participation in decision-making," Journal of Industrial Engineering and Engineering Management, vol. 29, no. 4, pp. 213-221, 2015.

[14] Y. Feng and J. M. Gu, "Coordination in a fresh agri-products supply chain considering TPL service provider's leading priority," Systems Engineering, vol. 34, no. 11,pp. 112-118, 2016.

[15] G. X. Yao, P. Q. Dai, J. Xu and D. M. Zhang, "Research on the fresh incentive mechanism for agricultural products logistics outsourcing under the framework of dual information asymmetry," Industrial Engineering and Management, vol. 23, no. 4, pp. 156-162, 2018.

[16] G. S. Xu and Z. L. Song, "Coordinating contract between fresh agricultural products e-business enterprise and logistics service provider-an analysis based on fresh agricultural products home delivery mode," Commercial Research, vol. 2, pp. 151-159, 2017.

[17] C.-Y. Dye and T.-P. Hsieh, "An optimal replenishment policy for deteriorating items with effective investment in preservation technology," European Journal of Operational Research, vol. 218, no. 1, pp. 106-112, 2012.

[18] Y.-P. Lee and C.-Y. Dye, "An inventory model for deteriorating items under stock-dependent demand and controllable deterioration rate," Computers \& Industrial Engineering, vol. 63 , no. 2 , pp. 474-482, 2012.

[19] L. Wang and B. Dan, "Coordination of fresh agricultural supply chain considering retailer's freshness-keeping and consumer utility," Operations Research and Management Science, vol. 24, no. 5, pp. 44-51, 2015.

[20] C.-Y. Dye, C.-T. Yang, and B. Lev, "Optimal dynamic pricing and preservation technology investment for deteriorating products with reference price effects," Omega, vol. 62, pp. 52-67, 2016.

[21] M. Ghazanfari, H. Mohammadi, M. S. Pishvaee, and E. Teimoury, "Fresh-product trade management under governmentbacked incentives: a casestudy of fresh flower market," IEEE Transactions on Engineering Management, vol. 66, no. 4, pp. 774-787, 2018.

[22] H. Mohammadi, M. M. Ghazanfari, and S. Pishvaee, E. Teymouri, "The revenue and preservation-technology investment sharing contract in the fresh-product supply chain: a game-theoretic approach," Journal of Industrial and Systems Engineering, vol. 11, pp. 132-149, 2018.

[23] J. Ji, Z. Zhang, and L. Yang, "Carbon emission reduction decisions in the retail-/dual-channel supply chain with consumers' preference," Journal of Cleaner Production, vol. 141, pp. 852-867, 2017.

[24] M. Rabbani, S. A. A. Hosseini-Mokhallesun, A. H. Ordibazar, and H. Farrokhi-Asl, "A hybrid robust possibilistic approach for a sustainable supply chain location-allocation network design," International Journal of Systems Science: Operations \& Logistics, pp. 1-16, 2018.

[25] X. Chen, S. Benjaafar, and A. Elomri, “The carbon-constrained EOQ," Operations Research Letters, vol. 41, no. 2, pp. 172-179, 2013. 
[26] N. Kazemi, S. H. Abdul-Rashid, R. A. R. Ghazilla, E. Shekarian, and S. Zanoni, "Economic order quantity models for items with imperfect quality and emission considerations," International Journal of Systems Science: Operations \& Logistics, vol. 5, no. 2, pp. 99-115, 2018.

[27] X. Yongmei and H. Xie, "Consumer environmental awareness and coordination in closed-loop supply," Open Journal of Business \& Management, vol. 4, no. 3, pp. 427-438, 2016.

[28] R. Sayyadi and A. Awasthi, "A simulation-based optimisation approach for identifying key determinants for sustainable transportation planning," International Journal of Systems Science: Operations \& Logistics, vol. 5, no. 2, pp. 161-174, 2018.

[29] Y. Hao, P. Helo, and A. Shamsuzzoha, "Virtual factory system design and implementation: integrated sustainable manufacturing," International Journal of Systems Science: Operations \& Logistics, vol. 5, no. 2, pp. 116-132, 2018.

[30] Y.-C. Tsao, "Design of a carbon-efficient supply-chain network under trade credits," International Journal of Systems Science: Operations \& Logistics, vol. 2, no. 3, pp. 177-186, 2015.

[31] R. Dubey, A. Gunasekaran, and T. Singh, "Building theory of sustainable manufacturing using total interpretive structural modelling," International Journal Of Systems Science: Operations \& Logistics, vol. 2, no. 4, pp. 231-247, 2015.

[32] C. Duan, C. Deng, A. Gharaei, J. Wu, and B. Wang, "Selective maintenance scheduling under stochastic maintenance quality with multiple maintenance actions," International Journal of Production Research, vol. 56, no. 23, pp. 7160-7178, 2018.

[33] Z. Liu, T. D. Anderson, and J. M. Cruz, "Consumer environmental awareness and competition in two-stage supply chain," European Journal of Operational Research, vol. 218, no. 3, pp. 602-613, 2012.

[34] M. R. Ready, K. G. Srinivasa, and B. E. Reddy, "Smart Vehicular System Based on the Internet of Things," Journal of Organizational and End User Computing, vol. 30, no. 3, pp. 4562, 2018.

[35] B. C. Giri and S. Bardhan, "Coordinating a supply chain with backup supplier through buyback contract under supply disruption and uncertain demand," International Journal of Systems Science: Operations \& Logistics, vol. 1, no. 4, pp. 193204, 2014.

[36] S. Yin, T. Nishi, and G. Zhang, "A game theoretic model for coordination of single manufacturer and multiple suppliers with quality variations under uncertain demands," International Journal of Systems Science: Operations \& Logistics, vol. 3, no. 2, pp. 79-91, 2016.

[37] D. Ghosh and J. Shah, "supply chain analysis under green sensitive consumer demand and cost sharing contract," International Journal of Production Economics, vol. 164, pp. 319-329, 2015.

[38] S.-B. Tsai, Y. Xue, J. Zhang et al., "Models for forecasting growth trends in renewable energy," Renewable and Sustainable Energy Reviews, vol. 77, pp. 1169-1178, 2017.

[39] W. Liu, H.-B. Shi, Z. Zhang et al., "The Development evaluation of economic zones in China," International Journal of Environmental Research and Public Health, vol. 15, no. 1, page. 56, 2018.

[40] S.-B. Tsai, Y. Jian, L. Ma et al., "A study on solving the production process problems of the photovoltaic cell industry," Renewable and Sustainable Energy Reviews, vol. 82, pp. 3546-3553, 2018.
[41] B. Liu, T. Li, and S.-B. Tsai, "Low carbon strategy analysis of competing supply chains with different power structures," Sustainability, vol. 9, 835 pages, 2017.

[42] S.-B. Tsai, "Using the DEMATEL model to explore the job satisfaction of research and development professionals in China's photovoltaic cell industry," Renewable and Sustainable Energy Reviews, vol. 81, pp. 62-68, 2017.

[43] S.-B. Tsai, M.-F. Chien, Y. Xue et al., "Using the fuzzy DEMATEL to determine environmental performance: a case of printed circuit board industry in Taiwan," PLOS ONE, vol. 10, no. 6, p. e0129153, 2015.

[44] L. Fabisiak, "Web service usability analysis based on user preferences," Journal of Organizational and End User Computing, vol. 30, no. 4, pp. 1-13, 2018.

[45] A. Avdic, "Second order interactive end user development appropriation in the public sector: application development using spreadsheet programs," Journal of Organizational and End User Computing, vol. 30, no. 1, pp. 82-106, 2018.

[46] J. Su, C. Li, S.-B. Tsai, H. Lu, A. Liu, and Q. Chen, "A sustainable closed-loop supply chain decision mechanism in the electronic sector," Sustainability, vol. 10, no. 4, page. 1295, 2018.

[47] S. B. Tsai, "Using grey models for forecasting China's growth trends in renewable energy consumption," Clean Technologies and Environmental Policy, vol. 18, no. 2, pp. 563-571, 2016.

[48] L. K. Huang, "A cultural model of online banking adoption: long-term orientation perspective," Journal of Organizational and End User Computing, vol. 29, no. 1, pp. 1-22, 2017.

[49] Y. Li and X. Wang, "Seeking health information on social media: a perspective of trust, self-determination, and social support," Journal of Organizational and End User Computing, vol. 30, no. 1, pp. 1-12, 2018. 